\title{
Homoeologous chromosome pairing in the distant hybrid Alstroemeria aurea $x$ A. inodora and the genome composition of its backcross derivatives determined by fluorescence in situ hybridization with species-specific probes
}

\author{
SILVAN A. KAMSTRA*, M. S. RAMANNA, MARJ O J . DE J EU, ANJ A G. J . KUIPERS \\ \& EVERT J ACOBSEN \\ Laboratory of Plant Breeding, The Graduate School of Experimental Plant Sciences, Wageningen Agricultural \\ University, PO Box 386, 6700 AJ Wageningen, The Netherlands
}

\begin{abstract}
A distant hybrid between two diploid species $(2 n=2 \mathrm{x}=16)$, Alstroemeria aurea and $A$. inodora, was investigated for homoeologous chromosome pairing, crossability with $A$. inodora and chromosome transmission to its $\mathrm{BC}_{1}$ offspring. Fluorescence in situ hybridization (FISH) with two species-specific probes, A001-I (A. aurea specific) and D32-13 (A. inodora specific), was used to analyse chromosome pairing in the hybrid and the genome constitution of its $\mathrm{BC}_{1}$ progeny plants. High frequencies of associated chromosomes were observed in both genotypes of the $\mathrm{F}_{1}$ hybrid, A1P2-2 and A1P4. In the former, both univalents and bivalents were found at metaphase I, whereas the latter plant also showed tri- and quadrivalents. Based on the hybridization sites of DNA probes on the chromosomes of both parental species, it was established that hybrid A1P4 contains a reciprocal translocation between the short arm of chromosome 1 and the long arm of chromosome 8 of $A$. inodora. Despite regular homoeologous chromosome pairing in $30 \%$ of the pollen mother cells, both hybrids were highly sterile. They were backcrossed reciprocally with one of the parental species, A. inodora. Two days after pollination, embryo rescue was applied and, eventually, six $\mathrm{BC}_{1}$ progeny plants were obtained. Among these, two were aneuploids $(2 n=2 x+1=17)$ and four were triploids $(2 n=3 \mathrm{x}=24)$. The aneuploid plants had originated when the interspecific hybrid was used as a female parent, indicating that $n$ eggs were functional in the hybrid. In addition, $2 n$ gametes were also functional in the hybrid, resulting in the four triploid $\mathrm{BC}_{1}$ plants. Of these four plants, three had received $2 n$ pollen grains from the hybrid and one a $2 n$ egg. Using FISH, homoeologous crossing over between the chromosomes of the two parental species in the hybrid was clearly detected in all $\mathrm{BC}_{1}$ plants. The relevance of these results for the process of introgression and the origin of $n$ and $2 n$ gametes are discussed.
\end{abstract}

Keywords: Alstroemeria, backcross progeny, fluorescence in situ hybridization, homoeologous recombination, species-specific tandem repeat, wide hybrid.

\section{Introduction}

More than a hundred species have so far been listed in the genus Alstroemeria. Most of them occur in two geographically distant South American regions, namely Chile and Brazil (Aker \& Healy, 1990).

*Correspondence. E-mail: silvan.kamstra@users.pv.wau.nl
Most of the species are diploid $(2 n=2 \mathrm{x}=16)$, possess large chromosomes and asymmetric karyotypes (Tsuchiya \& Hang, 1989; Buitendijk \& Ramanna, 1996) and have large genome sizes (Buitendijk et al., 1997). The genomes of the species are highly differentiated, especially between Chilean and Brazilian species. Such differentiation is evident at three levels: (i) sexual hybridization between 
species is generally not possible without the help of embryo rescue (Buitendijk et al., 1995; De Jeu \& Jacobsen, 1995); (ii) compared with homologous chromosome pairing in the parental species, homoeologous chromosome pairing in the interspecific hybrids is greatly reduced (Ramanna 1991, 1992; Lu \& Bridgen, 1997); (iii) the genomes of individual species clearly differ with respect to the molecular organization of repetitive DNA sequences among the Chilean species as well as between the Chilean and Brazilian species (Kuipers et al., 1997).

Once obtained, interspecific Alstroemeria hybrids are usually vigorous and also highly sterile, producing no or very few viable pollen grains (Goemans, 1962; M. S. Ramanna \& J. H. Buitendijk, unpublished observation). In these hybrids, a disturbed meiosis is often observed, which is probably associated with the high degree of sterility. Nevertheless, viable gametes occur rarely in the hybrids and have been used by the cut flower breeders to produce numerous, mainly complex polyploid cultivars (Ramanna, 1991). The viable gametes can also be used in breeding programmes in order, for example, to introgress alien chromosomes or chromosome segments into other species. Because one of the most reliable ways of achieving stable introgression of desired characteristics is homoeologous recombination, it is interesting to study whether homoeologous chromosome pairing and recombination occur in interspecific Alstroemeria hybrids.

The large and easily identifiable chromosomes of the Alstroemeria species contain multiple ribosomal DNA sites and sites for species-specific tandem repeats, which can be used as cytological markers to identify individual chromosomes and genomes (Kamstra et al., 1997). For A. aurea, a Chilean species, and $A$. inodora, a Brazilian species, FISH karyotypes were constructed using two speciesspecific probes and two ribosomal probes, which allowed identification of all individual chromosomes (Kamstra et al., 1997). The species-specific probes, A001-I, specific for $A$. aurea, and D32-13, specific for $A$. inodora, can be used simultaneously in FISH experiments to identify the parental genomes and chromosomes in the interspecific hybrid.

In the present study, FISH with two speciesspecific probes was used to analyse homoeologous chromosome pairing in interspecific hybrids between the Chilean species $A$. aurea and the Brazilian species $A$. inodora. With the long-term objective of introgressing segments of $A$. aurea into $A$. inodora, it is essential to know whether, and with what frequency, recombination occurs between homoeologous chromosomes, because this is a prerequisite for stable introgression. In addition, the interspecific hybrid was backcrossed to $A$. inodora. The backcross progeny was analysed with FISH to test whether these were the result of the backcross and to gain more insight into the type of viable gametes that are produced in this highly sterile hybrid.

\section{Materials and methods}

Plant material and backcrossing of the interspecific hybrid

The accessions A1P2-2 and A1P4 of the hybrid $A$. aurea $\times A$. inodora were produced using embryo rescue techniques (Buitendijk et al., 1995). These hybrids were backcrossed with the $A$. inodora parent ( $\mathrm{P} 2$ or $\mathrm{P} 4$ respectively). The hybrids and $A$. inodora were diploid $(2 n=2 \mathrm{x}=16)$. Two days after pollination, embryo rescue was applied as described by De Jeu \& Jacobsen (1995). The ovules were dissected 2-3 days after pollination, placed on MS90 medium (Murashige \& Skoog, 1962) and transferred 6 weeks later to MS30 (Murashige \& Skoog, 1962) to induce germination of the embryos. Germinated ovules were transferred to AV4 medium [MS salts, $20 \mathrm{~g} \mathrm{~L}^{-1}$ sucrose, $0.5 \mathrm{mg} \mathrm{L}^{-1}$ 6-benzylaminopurine (BAP), $\mathrm{pH}$ 6.2], and the plants obtained were grown in a greenhouse.

\section{Chromosome preparations}

For meiotic preparations, anthers of the hybrids A1P2-2 and A1P4 were fixed for 1-2 $\mathrm{h}$ in ethanolacetic acid (3:1) and stored in 70\% ethanol until use. Anthers containing pollen mother cells (PMCs) were digested with pectolytic enzymes $(0.4 \%$ pectolyase $\mathrm{Y} 23,0.4 \%$ cellulase RS and $0.4 \%$ cytohelicase) for $2-3 \mathrm{~h}$ at $37^{\circ} \mathrm{C}$. The macerated anthers were squashed in $45 \%$ acetic acid or $2 \%$ acetocarmine. The preparations were frozen in liquid nitrogen and, after removal of the coverslips, briefly washed in absolute ethanol, air dried and stored at $4^{\circ} \mathrm{C}$ until further use.

For mitotic preparations, fast-growing root tips of backcross plants were collected in 8-hydroxyquinoline, stored overnight at $4^{\circ} \mathrm{C}$ and fixed in ethanolacetic acid (3:1). Chromosome preparations were made as described by Kuipers et al. (1997). Chromosome numbers were counted in all $\mathrm{BC}_{1}$ plants obtained.

Lactophenol acid-fuchsin stain was used to estimate the frequency of viable pollen grains in the hybrids and some $\mathrm{BC}_{1}$ plants. At least 500 pollen grains were counted per plant. Only fully stained pollen grains were scored as viable. 


\section{DNA probes and labelling}

Two species-specific DNA sequences were used in this study to identify the parental chromosomes in the $\mathrm{F}_{1}$ hybrid and its derivatives. The probes A001-I and D32-13, specific for $A$. aurea and $A$. inodora, respectively (De Yeu et al., 1997; Kamstra et al., 1997; G. J. Kuipers et al., unpubl. data), hybridize to all chromosomes of either $A$. aurea or $A$. inodora (Kamstra et al., 1997), except for chromosome 1, which was detected by neither probe. The hybridization patterns for both probes on each individual chromosome of the two species are indicated in Fig. 1. In addition, two ribosomal probes pTa71(18S-5.8S-25S rDNA; Gerlach \& Bedbrook, 1979) and pTa794 (5S rDNA; Gerlach \& Dyer, 1980) were used in some experiments to study the chromosomes in more detail.

All probes were labelled by polymerase chain reaction (PCR) with either digoxigenin-11-dUTP or biotin-16-dUTP (both from Boehringer Mannheim) except pTa71, which was labelled by nick translation with biotin-16-dUTP.

\section{Fluorescence in situ hybridization (FISH)}

The pretreatment and hybridization steps applied to meiotic and mitotic preparations were performed as described in Kamstra et al. (1997). For meiotic preparations, the pretreatment with pepsin was increased from $10 \mathrm{~min}$ to $25 \mathrm{~min}$ at $37^{\circ} \mathrm{C}$. Digoxigenin-11-dUTP- and biotin-1-dUTP-labelled probes were detected with fluorescein isothiocyanate (FITC)- and Cy3-conjugated antibodies respectively (for details, see Kamstra et al., 1997).

Chromosome preparations were counterstained with DAPI (4,6-diamidino-2-phenylindole). Slides were examined using a Zeiss Axiophot fluorescence microscope, and photographs were taken on 400 ASA colour negative film. All triple exposures were made with a triple bandpass filter for DAPI, FITC and $\mathrm{Cy} 3$, using separate excitation filters for each fluorochrome. Negatives were scanned at $500 \mathrm{dpi}$ and processed using routine image-processing software.

\section{Results}

Meiotic behaviour and crossability of the $F_{1}$ hybrid $A$. aurea $\times A$. inodora

FISH with the probes A001-I and D32-13 to spread preparations of pollen mother cells revealed a clear distinction of the $A$. aurea and $A$. inodora chromosomes (Fig. 2a-f). As a result, homoeologous associations could be identified as well as univalents. Most surprising in A1P2-2 was the large variation in homoeologous associations ranging from two to

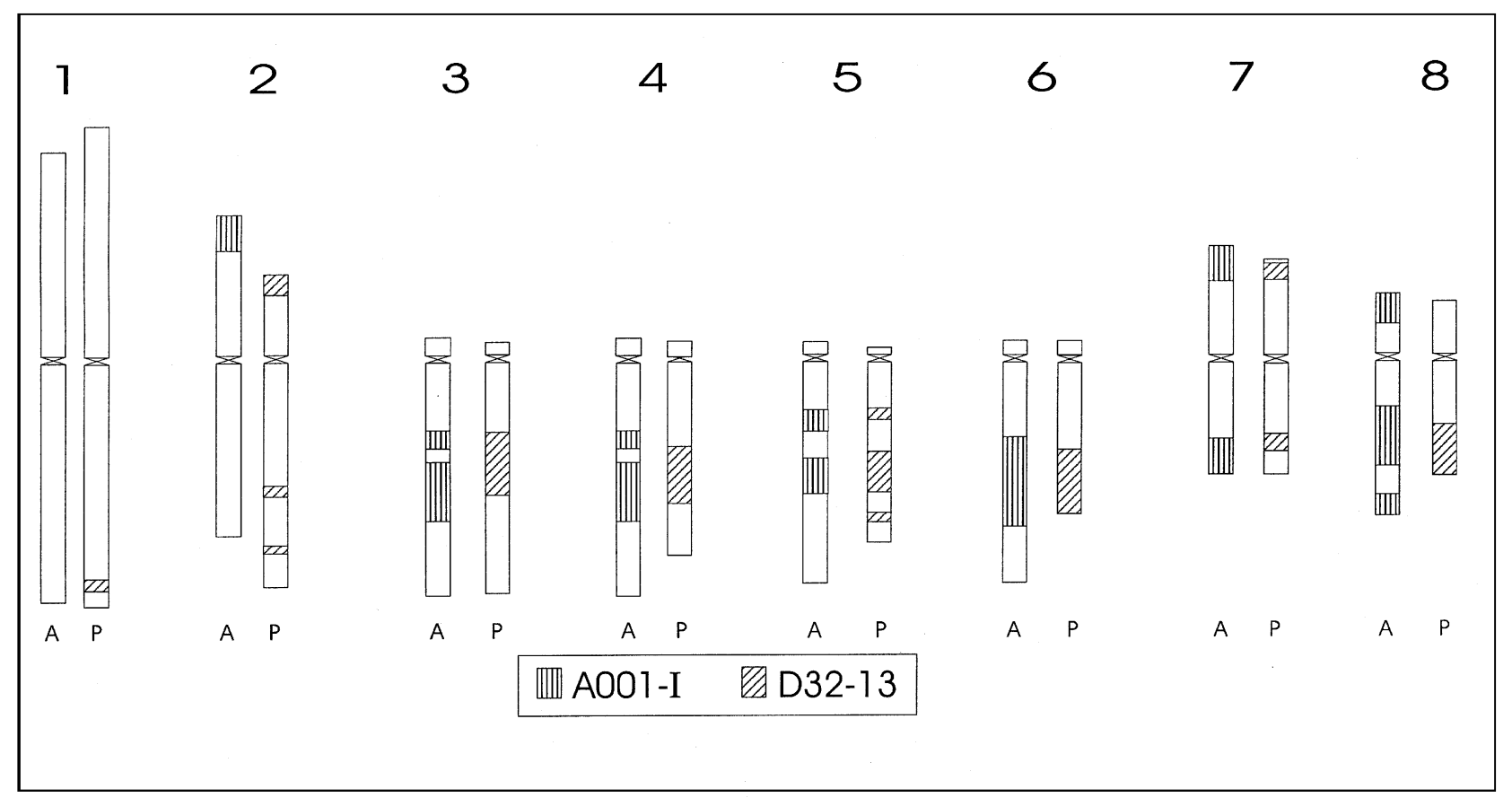

Fig. 1 Ideogram showing the hybridization patterns of both species-specific probes A001-I and D32-13 for each individual chromosome of Alstroemeria aurea (A) and A. inodora (P) (for details see Kamstra et al., 1997). 


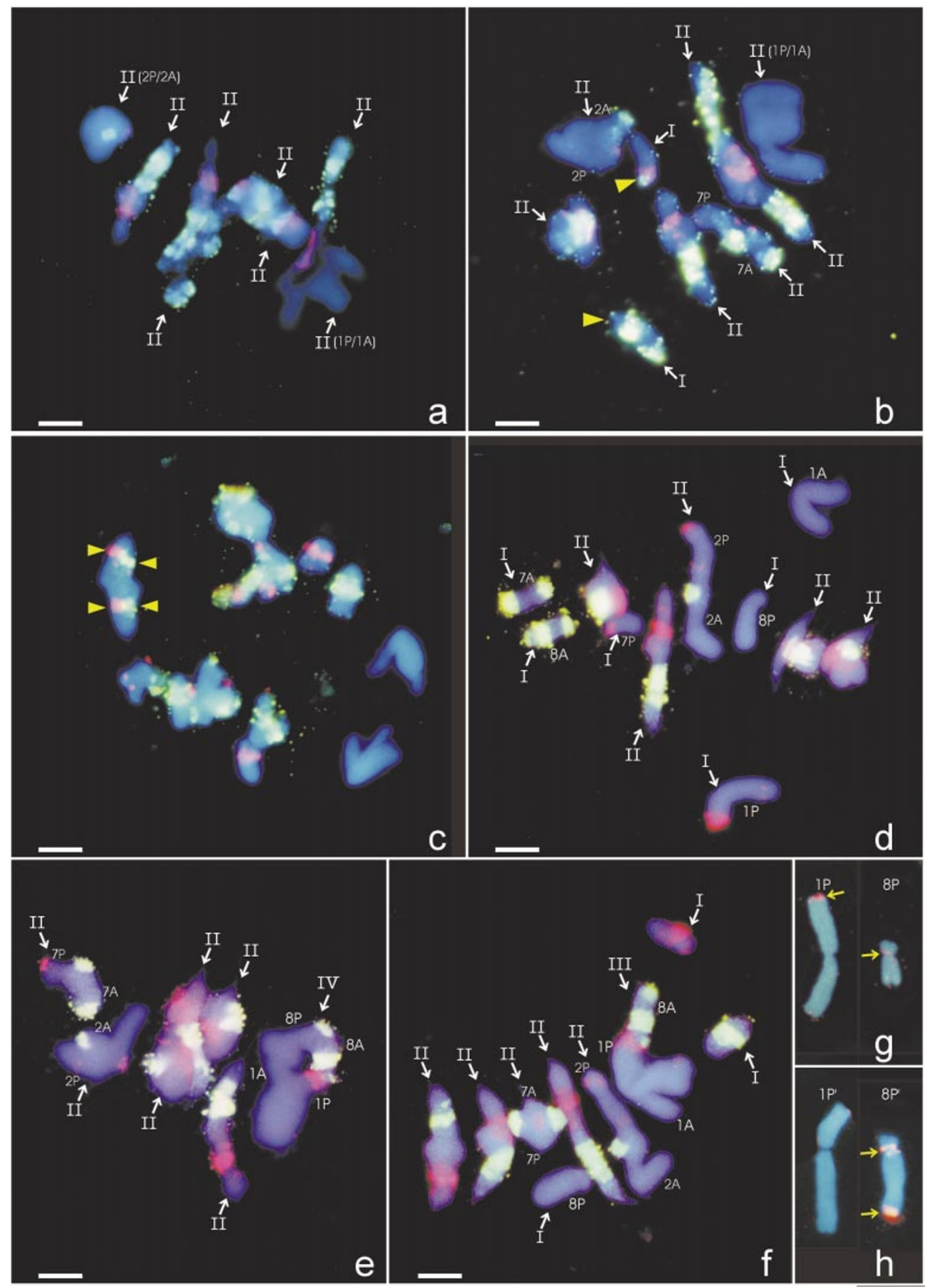

(C) The Genetical Society of Great Britain, Heredity, 82, 69-78. 
Fig. 2 FISH using two species-specific DNA probes to meiotic metaphase I/anaphase I spreads of the Alstroemeria aurea $\times A$. inodora interspecific hybrids A1P2-2 and A1P4. The D32-13 probe was labelled with biotin and detected with Cy3-conjugated antibodies (red). The A001-I probe was labelled with digoxigenin and detected with FITC-conjugated antibodies (green). DAPI (blue) was used as counterstain. Chromosome configurations are indicated (I = univalent, $\mathrm{II}=$ bivalent, III = trivalent and IV = quadrivalent). Also, chromosomes that could be identified on the basis of their hybridization patterns are indicated. (a-c) FISH to metaphase I and anaphase I spreads of hybrid A1P2-2. (a) Complete chromosome pairing (eight bivalents) in A1P2-2. (b) Seven bivalents and two univalents at metaphase I. The univalents already possess exchanged segments (yellow arrows), indicating precocious separation of a bivalent. (c) Anaphase I of hybrid A1P2-2. With both species-specific probes, it is possible to detect crossover in the lagging chromosome pair (yellow arrows). (d-f) FISH to metaphase I spreads of hybrid A1P4. The chromosomes 1A, 1P, 8A and 8P are indicated. Note the four univalents (d), trivalent + univalent (f) and quadrivalent (e) configurations of these chromosomes. (g-h) Normal and altered mitotic chromosomes $1 \mathrm{P}$ and $8 \mathrm{P}$ of hybrid A1P2-2 (g) and A1P4 (h) hybridized with biotinylated pTa71 probe detected with Cy3-conjugated antibodies. The arrows indicate the same hybridization sites. Note the altered morphology of both chromosomes. Scale bars represent $10 \mu \mathrm{m}$.

eight bivalents per complement. The average number of bivalents per pollen mother cell (PMC) was 6.7 . In $30 \%$ of the PMCs, the maximum number of eight bivalents (Table 1) was observed, indicating that every $A$. aurea chromosome was associated with its homoeologous counterpart in the $A$. inodora genome. In some cells, univalents were found to which both species-specific probes hybridized (Fig. $2 b$, yellow arrowheads), indicating that these resulted from precocious separation of bivalents.

Unlike A1P2-2, PMCs of A1P4 often contained one multivalent chromosome association, consisting of a tri- or quadrivalent (Fig. 2e and f, Table 1). An obvious explanation for these multivalents was the presence of a reciprocal translocation, because the same (homoeologous) pairs of chromosomes 1 and 8 of $A$. aurea and $A$. inodora were always involved. Confirmation came from FISH analysis using the species-specific probes and both ribosomal probes (pTa71 and pTa794) to mitotic preparations, as this revealed two normal and two translocation chromosomes. Identification was based on the following criteria (see Kamstra et al., 1997).

1 No hybridization sites for any of the probes used were detected on chromosome 1 of $A$. aurea. In addition, the morphology of this chromosome was not altered.

2 Chromosome 1 of $A$. inodora (1P), normally containing the minor D32-13 and pTa794 hybridization sites on the long arm and a diagnostic pTa71 site on the short arm, underwent two morphological alterations. One of its arms became shorter (Fig. $2 \mathrm{~g}$ and $\mathrm{h}$ ), and a prominent D32-13 site was observed on this arm, whereas the expected pTa71 site was not present.

3 Chromosome 8 of $A$. aurea (8A) retained its original shape with three hybridization sites for A001-I.

4 Chromosome 8 of $A$. inodora (8P) was altered morphologically with a long arm about twice as long compared with the parental species. On this long arm, a distal pTa71 hybridization site was detected instead of the expected D32-13 site (Fig. 2g and h).

Both hybrids A1P2-2 and A1P4 had a very low frequency $(3 \%)$ of stainable pollen, indicating that they were highly male sterile. Nevertheless, a fairly extensive attempt was made to backcross both genotypes to the parent $A$. inodora (Table 2). Hybrid A1P2-2 was used both as female and as male parent in combination with accession P2. After 6 weeks of ovule culture, a few ovules germinated and

Table 1 Chromosome associations at metaphase $\mathrm{I}$ in two plants of the $\mathrm{F}_{1}$ hybrid, Alstroemeria aurea $\times$ A. inodora, analysed by FISH

\begin{tabular}{lcccccr}
\hline & & & \multicolumn{3}{c}{$\begin{array}{c}\text { Average number of chromosome } \\
\text { configurations per metaphase I }\end{array}$} \\
\cline { 3 - 7 } Hybrid & $\begin{array}{c}\text { No. of cells } \\
\text { analysed }\end{array}$ & $\begin{array}{c}\text { \% of cells with complete } \\
\text { chromosome pairing }\end{array}$ & I & II & III & IV \\
\hline A1P2-2 & 167 & $30^{*}$ & 2.5 & 6.7 & - & -1.3 \\
A1P4 & 15 & $20 \dagger$ & 2.1 & 5.7 & 0.4 & 0.3 \\
\hline
\end{tabular}

*Percentage of cells containing eight bivalents.

$\dagger$ Percentage of cells containing eight bivalents or six bivalents and one quadrivalent (see text).

(c) The Genetical Society of Great Britain, Heredity, 82, 69-78. 
produced callus structures; however, most of these structures eventually died. Six plants were obtained from the backcrosses of the $A$. aurea $\times A$. inodora hybrid (A1P2-2); three each in both directions of crossing. All were grown to maturity in a greenhouse where some of them flowered after 18 months from the time the initial crosses were made. Unlike the $F_{1}$ hybrid, the pollen stainability in these $\mathrm{BC}_{1}$ plants was considerably higher (19\% in $96 \mathrm{SK} 402,22 \%$ in 95SK04 and 58\% in 95SK17). In contrast to A1P2-2, backcrossing was not successful in the case of A1P4.

\section{Analysis of $\mathrm{BC}_{1}$ plants}

The somatic chromosome numbers were determined in all six $\mathrm{BC}_{1}$ plants. Four plants possessed triploid chromosome numbers $(2 n=3 \mathrm{x}=24)$, and two were aneuploids $(2 n=2 \mathrm{x}=16+1)$ (Table 3$)$. Considering the chromosome numbers (Fig. 3a-f), it was evident that all plants were backcross derivatives. Further- more, the different ploidy levels of the six progeny plants indicated that both $n$ and $2 n$ gametes were functional in these crosses. The two aneuploid plants, 95SK11 and 95SK18, had originated from the cross in which the $\mathrm{F}_{1}$ hybrid, A1P2-2, was used as the female, indicating that haploid gametes were functional in the $F_{1}$ hybrid.

The presence of chromosomes of both parental species in the $\mathrm{BC}_{1}$ plants was confirmed by FISH using the two species-specific probes (Fig. 3a-f). In all plants except 95SK17, chromosomes were observed to which both species-specific probes hybridized (Fig. 3a-f, arrows). These chromosomes are probably the result of meiotic recombination in the $F_{1}$ hybrid. The number of recombinant chromosomes ranged from none (in 95SK17) to five (in 95SK402) (Table 3). In addition, some of the other chromosomes of the $\mathrm{BC}_{1}$ plants lacked expected hybridization sites, suggesting that these chromosomes were also recombinant (Table 3 ).

Table 2 Parentage and origin of six $\mathrm{BC}_{1}$ plants produced through ovule culture from backcrossing the $\mathrm{F}_{1}$ hybrid (Alstroemeria aurea $\times A$. inodora) to the parent, $A$. inodora

\begin{tabular}{llcccc}
\hline $\begin{array}{l}\text { Female parent } \\
(\text { code })\end{array}$ & $\begin{array}{c}\text { Male parent } \\
(\text { code })\end{array}$ & $\begin{array}{c}\text { No. of crosses } \\
\text { made }\end{array}$ & $\begin{array}{c}\text { No. of } \\
\text { germinated } \\
\text { ovules }\end{array}$ & $\begin{array}{c}\text { No. of } \mathrm{BC}_{1} \\
\text { plants } \\
\text { obtained }\end{array}$ & $\begin{array}{c}\text { Codes of } \mathrm{BC}_{1} \\
\text { plants }\end{array}$ \\
\hline $\begin{array}{l}\text { A. inodora } \\
(\mathrm{P} 2)\end{array}$ & $\begin{array}{c}\text { A. aurea } \times \text { A. inodora } \\
\text { (A1P2-2) }\end{array}$ & 105 & 44 & $\mathbf{3}$ & $($ 95SK17, 96SK402, 95SK403) \\
$\begin{array}{l}\text { A. aurea } \times \text { A. inodora } \\
(\text { A1P2-2) }\end{array}$ & $\begin{array}{c}\text { Anodora } \\
\text { (P2) }\end{array}$ & 107 & 7 & $\mathbf{3}$ & (95SK04, 95SK18, 95SK11) \\
$\begin{array}{l}\text { A. aurea } \times \text { A. inodora } \\
\text { (A1P4) }\end{array}$ & $\begin{array}{c}\text { A. inodora } \\
\text { (P4) }\end{array}$ & 87 & - & - & \\
\hline
\end{tabular}

Table 3 Observed total number of chromosomes and the number of chromosomes containing hybridization signals for the species-specific probes in six $\mathrm{BC}_{1}$ plants

\begin{tabular}{|c|c|c|c|c|c|}
\hline \multirow[b]{2}{*}{$\mathrm{BC}_{1}$ plant } & \multirow{2}{*}{$\begin{array}{l}\text { No. of } \\
\text { chromosomes } \\
(2 n)\end{array}$} & \multicolumn{3}{|c|}{ No. of chromosomes with } & \multirow[b]{2}{*}{ No signals $\dagger$} \\
\hline & & $\begin{array}{l}\text { A001-I and } \\
\text { D32-13 }\end{array}$ & $\begin{array}{l}\text { A001-I* } \\
\text { only }\end{array}$ & $\begin{array}{l}\text { D32-13* } \\
\text { only }\end{array}$ & \\
\hline Hybrid (A1P2-2) $\ddagger$ & 16 & - & 7 & 7 & 2 \\
\hline 95SK11§ & 17 & 1 & $3(1)$ & $12(2)$ & 1 \\
\hline 95SK18 & 17 & 1 & $4(1)$ & $10(1)$ & 2 \\
\hline 95SK17 & 24 & 0 & $6(0)$ & $15(0)$ & 3 \\
\hline 95SK04 & 24 & 4 & $5(1)$ & $12(1)$ & 3 \\
\hline 96SK402 & 24 & 5 & $3(0)$ & $13(3)$ & 3 \\
\hline 96SK403 & 24 & 3 & $5(0)$ & $13(0)$ & 3 \\
\hline
\end{tabular}

*Numbers between brackets indicate the number of chromosomes with an unexpected number of hybridization sites. $\dagger$ In some cases, a small signal for the D32-13 probe was observed, but the signal was not present in all cells analysed. $\ddagger$ See Kamstra et al. (1997).

$\S$ Frequently, 34 chromosomes per cell were counted instead of 17 chromosomes. 


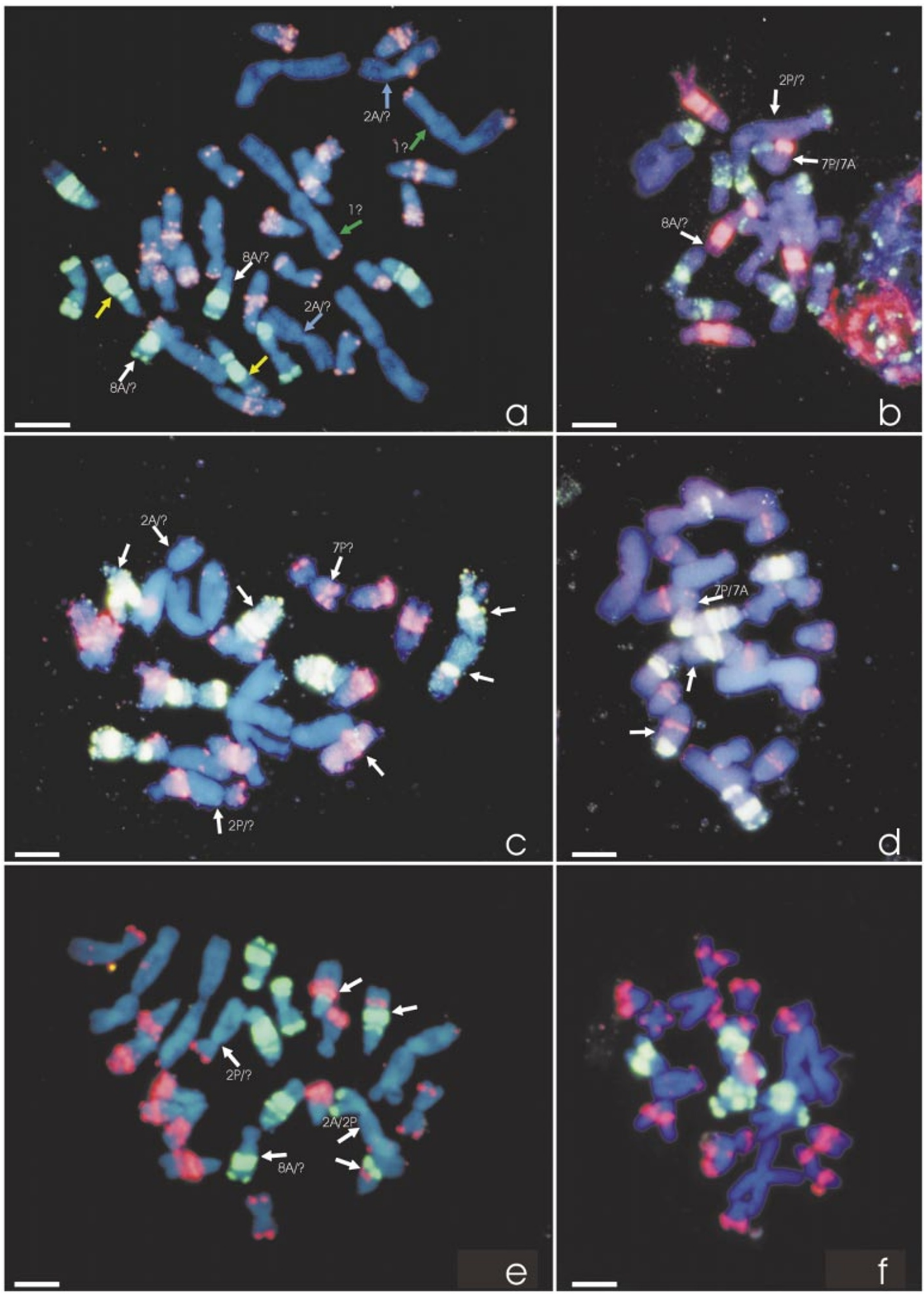

(c) The Genetical Society of Great Britain, Heredity, 82, 69-78. 
Fig. 3 FISH with two species-specific probes applied to mitotic spreads of six $\mathrm{BC}_{1}$ plants obtained after backcrossing the Alstroemeria aurea $\times$ A. inodora hybrid with $A$. inodora. The probes were D32-13 (Cy3, red) and A001-I (FITC, green) in all figures (a, c-f) except (b), in which the labelling of the probes was reversed. Arrows indicate recombinant chromosomes. The identifiable recombinant chromosomes are indicated. (a) A doubled cell $(2 n=4 \mathrm{x}=34)$ of the aneuploid $\mathrm{BC}_{1}$ plant 95SK11 (one chromosome 7P is missing). Coloured arrows indicate pairs of recombinant chromosomes. (b) The aneuploid $\mathrm{BC}_{1}$ plant 95SK18 with A001-I (red, Cy3) and D32-13 (green, FITC). (c) The triploid BC $_{1}$ plant 96 SK402 $(2 n=3 \mathrm{x}=24)$. (d) The triploid $\mathrm{BC}_{1}$ plant 96SK403. (e) The triploid $\mathrm{BC}_{1}$ plant $(2 n=3 \mathrm{x}=24) 95 \mathrm{SK} 04$. (f) The triploid $(2 n=3 \mathrm{x}=24) 95 \mathrm{SK} 17$. No recombinant chromosomes were found in this $\mathrm{BC}_{1}$ plant. Scale bars represent $10 \mu \mathrm{m}$.

FISH with species-specific probes on the triploid $\mathrm{BC}_{1}$ plants proved that functional $2 n$ gametes were formed in the $F_{1}$ hybrid. In all these plants, one intact genome of $A$. inodora was present, except for 95SK17, in which it seems that two complete genomes of $A$. inodora were present. One complete genome of $A$. inodora is expected, because this was the recurrent backcross parent. Considering the direction of the backcrosses, $2 n$ pollen was functional in the cases of 95SK17, 96SK402 and $96 \mathrm{SK} 403$, and $2 n$ eggs were functional in the case of 95SK04 (Table 3 ). In addition, both aneuploids were derived from functional $n$ eggs. One of the aneuploid plants, 95SK11, possessed spontaneously doubled somatic cells at a low frequency (Fig. 3a).

Of the $\mathrm{BC}_{1}$ plants, 95SK17 was successfully backcrossed to $A$. inodora (P2). This was an indication that $\mathrm{BC}_{2}$ plants can be obtained through further backcrossing of the $\mathrm{BC}_{1}$ plants.

\section{Discussion}

In this study, it has been shown that FISH with species-specific probes can be used to study chromosome associations in the interspecific hybrid $A$. aurea $\times A$. inodora and to analyse its backcross $\left(\mathrm{BC}_{1}\right)$ progeny. The simultaneous detection of these two probes enabled chromosomes belonging to either parent of the hybrid to be distinguished, thus allowing an accurate estimation of the number of bivalents per PMC and showing homoeologous recombination.

The parental species, being of different geographical origin, are highly diverged (Aker \& Healy, 1990). For example, the variation in the physical location of the ribosomal DNA sites, the abundant presence of species-specific tandem repeats on the chromosomes of both $A$. aurea and A. inodora (Kamstra et al., 1997) and the variation at the repetitive DNA sequence level (Kuipers et al., 1997) indicate that the genomes/chromosomes have diverged considerably. In addition, using genomic in situ hybridization (GISH), it is possible to distinguish both parental genomes in the hybrid (Kuipers et al., 1997). Despite this high degree of genome differentiation, high frequencies of bivalents were observed at metaphase I (MI) of the interspecific hybrid. This indicates that a certain degree of homology is still present between the chromosomes of both parental species. This homology is sufficient to enable chromosome pairing, as up to eight bivalents were observed in $30 \%$ of the PMCs of the hybrid, suggesting that, for each $A$. aurea chromosome, a homoeologous counterpart is present in $A$. inodora. However, the morphological comparison of karyotypes of the chromosomes of the parental species (Kamstra et al., 1997) did not establish which chromosomes are homoeologous. Based on further analysis, this was determined for all chromosomes of $A$. aurea and $A$. inodora (Kamstra et al., in press).

The observed variation in the number of associated chromosomes (range 2-8) per PMC combined with observed meiotic abnormalities, such as laggards and bridges at anaphase I (data not shown), indicate that the chromosomes of both species have diverged considerably. Variation in the number of associated chromosomes at MI was also observed in other hybrids between Alstroemeria species (Tsuchiya \& Hang, 1989; Ramanna, 1991; Lu \& Bridgen, 1997).

A reciprocal translocation was present between chromosomes $1 \mathrm{P}$ and $8 \mathrm{P}$ in hybrid A1P4. This chromosome aberration was not present in the parent $A$. inodora (accession P4), and chromosome pairing in this parent seemed to be normal, suggesting that the translocation occurred spontaneously during either the process of embryo rescue or the prolonged duration of in vitro culture of the plant material. The presence of this translocation might explain, to some extent, why no progeny was obtained from the hybrid A1P4.

The high frequencies of homoeologous associated chromosomes per PMC indicate considerable recombination between homoeologous chromosomes of $A$. aurea and A. inodora. This was clearly visible at anaphase I stages (Fig. 2c) and also in the karyotypes of the $\mathrm{BC}_{1}$ plants (Fig. 3a-f) because, in the $\mathrm{BC}_{1}$ plants, several chromosomes possessed hybridization signals either for A001-I as well as D32-13 or showed altered hybridization patterns 
(Table 3). Therefore, these species-specific probes are useful for detecting homoeologous recombination. However, because of the lack of hybridization sites for the species-specific probes to certain chromosome regions, it is possible that some recombination events were not detected through FISH. The large number of the recombinant chromosomes in the $\mathrm{BC}_{1}$ plants confirms that homoeologous recombination occurs in the interspecific hybrid. This is important for the introgression of (small) chromosome segments from $A$. aurea into $A$. inodora, which is one of the main objectives of producing these $\mathrm{BC}_{1}$ plants.

Despite the low frequencies of stainable pollen grains in the interspecific hybrid, progeny from the interspecific hybrid $A$. aurea $\times A$. inodora was obtained after extensive backcrossing and embryo rescue. Only a few plants were obtained from the 299 crosses in total $(\approx 7500$ ovules were cultured in vitro), indicating that the survival rate of the gametes is very low. However, from the number of germinated ovules that never developed into plants (Table 2), it can be concluded that some gametes actually do survive until this stage but, for unknown reasons, they are not able to survive. Therefore, it is interesting to determine what kind of gametes actually survived and resulted in $\mathrm{BC}_{1}$ progeny.

The two different ploidy levels (diploid and triploid) among the various $\mathrm{BC}_{1}$ plants indicate that viable $n$ and $2 n$ gametes are produced in the hybrid. In both reciprocal crosses, using the hybrid as either male or female parent, plants were obtained, indicating that the hybrid produced viable male and female gametes. Both $n$ and $2 n$ eggs were functional when the hybrid was used as a female parent, and only $2 n$ pollen grains were functional in the male parent. However, the number of $\mathrm{BC}_{1}$ plants is too small to conclude whether these observed differences between male and female gametes are meaningful.

Both diploid $\mathrm{BC}_{1}$ plants, which received $n$ gametes from the hybrid, contain one additional chromosome $(2 n=2 \mathrm{x}+1=17)$. Probably, this extra chromosome is the result of non-disjunction at metaphase I/anaphase I or a lagging chromosome during meiosis in the $F_{1}$ hybrid. These aneuploid plants showed abnormal development, which is probably caused by the presence of an extra chromosome.

The triploid $\mathrm{BC}_{1}$ plants received $2 n$ gametes from the hybrid. In theory, these $2 n$ gametes could also have been produced in the backcross parent $A$. inodora. However, the backcross parent $A$. inodora produces regular-shaped pollen grains, which is indicative of $n$ gametes. Furthermore, in all $\mathrm{BC}_{1}$ plants, only one complete genome (eight different chromosomes) of $A$. inodora was detected with FISH (additional GISH studies showed that $\mathrm{BC}_{1}$ plant 95SK17 also contains one complete genome of $A$. inodora; Kamstra et al., in press), instead of the two genomes that would result from $2 n$ gamete formation in the backcross parent $A$. inodora.

$2 n$ gametes have been found in other interspecific Alstroemeria hybrids (Ramanna, 1992; M. S. Ramanna \& J. H. Buitendijk, unpubl. obs.). Ramanna (1991) stated that the polyploid nature of the present cultivars is mainly the result of $2 n$ gamete formation in the hybrids. It is believed that, because of failure of chromosome pairing in the interspecific hybrids, the $2 n$ gametes originate through an equational division of the entire chromosome complement of the hybrid (Ramanna, 1983). This is the first division restitution (FDR) mechanism. Based on the number of chromosomes (especially the centromeres) of each of the parental species in the $\mathrm{BC}_{1}$ plants, it can be concluded that they obtained FDR gametes from the hybrid, which is confirmed by a combined GISH and FISH analysis of the $\mathrm{BC}_{1}$ plants (Kamstra et al., in press).

The $\mathrm{BC}_{1}$ plants were made with the main objective of introgressing $A$. aurea chromosomes into $A$. inodora. Only the triploid $\mathrm{BC}_{1}$ plants seem usable for this purpose, because the aneuploid $\mathrm{BC}_{1}$ plants show abnormal plant development and do not flower. The triploid plants, on the other hand, produce abundant flowers and stainable pollen, which indicates that they can be used to produce further backcross populations. In addition, the number of recombined chromosomes in the $\mathrm{BC}_{1}$ plants as a result of homoeologous recombination indicates that it is possible to introgress chromosome segments of $A$. aurea into $A$. inodora.

The development of molecular cytogenetic methods for the identification of individual chromosomes and genomes (for a review, see Jiang \& Gill, 1994) has provided very valuable cytological markers for monitoring the consequences of hybridization and the process of introgression using backcross derivatives. In particular, the aspects of homoeologous chromosome pairing, position and extent of crossing over and the gamete composition can be monitored more critically, as has clearly been demonstrated for Alstroemeria in the present study.

\section{Acknow ledgements}

The authors thank Dr Hans de Jong, Department of Genetics, Wageningen, for critical reading of the manuscript, and Unifarm, especially Michel Hagen- 
doorn, for taking care of the plants in the greenhouse.

\section{References}

AKER, S. AND HEALY, w. 1990. The phytogeography of the genus Alstroemeria. Herbertia, 46, 76-87.

BUITENDIJK, J. H. AND RAMANNA, M. s. 1996. Giemsa C-banded karyotypes of eight species of Alstroemeria L. and some of their hybrids. Ann. Bot., 78, 449-457.

BUITENDIJK, J. H., PINSONNEAUX, N., VAN DONK, A. C., RAMANNA, M. S. AND VAN LAMMEREN, A. A. M. 1995. Embryo rescue by half-ovule culture for the production of interspecific hybrids in Alstroemeria. Sci. Hort., 64, $65-75$.

BUITENDIJK, J. H., BOON, E. J. AND RAMANNA, M. S. 1997. Nuclear DNA content in twelve species of Alstroemeria L. and some of their hybrids. Ann. Bot., 79, 343-353.

DE JEU, M. J. AND JACOBSEN, E. 1995. Early postfertilization ovule culture in Alstroemeria L. and barriers to interspecific hybridization. Euphytica, 86, 15-23.

DE JEU, M. J., LASSCHUIT, J., KUIPERS, G. J., KAMSTRA, S. A. AND VISSER, R. G. F. 1997. Characterization and localisation of repetitive DNA sequences in the ornamental Alstroemeria aurea Graham. Theor. Appl. Genet., 94, 982-990.

GERLACH, W. L. AND BEDBRoOK, J. R. 1979. Cloning and characterization of ribosomal RNA genes from wheat and barley. Nucl. Acids Res., 7, 1869-1885.

GERLACH, W. L. AND DYER, T. A. 1980. Sequence organization of the repeating units in the nucleus of wheat which contain 5S rRNA genes. Nucl. Acids Res., 8, 4851-4865.

goemans, J. A. M. 1962. Breeding of Alstroemerias. $J$. $R$. Hort. Soc., 87, 282-284.

JIANG, J. AND GILL, B. s. 1994. Nonisotopic in situ hybridization and plant genome mapping: the first 10 years. Genome, 37, 717-725.

KAMSTRA, S. A., KUIPERS, A. G. J., DE JEU, M. J., RAMANNA, M. S. AND JACOBSEn, E. 1997. Physical localization of repetitive DNA sequences in Alstroemeria: karyotyping of two species with species specific and ribosomal DNA. Genome, 40, 652-658.

KAMSTRA, S. A., KUIPERS, A. G. J., DE JEU, M. J., RAMANNA, M. S. AND JACOBSEN, E. The extract and position of homoeologous recombination in a distant hybrid of Alstroemeria: a molecular cytogenetic assessment of first generation backcross progenies. Chromosoma, in press.

KUIPERS, A. G. J., VAN OS, D. P. M., DE JONG, J. H. AND RAMANNA, M. s. 1997. Molecular cytogenetics of Alstroemeria: identification of parental genomes in interspecific hybrids and characterization of repetitive DNA families in constitutive heterochromatin. Chrom. Res., 5, 31-39.

LU, C. AND BRIDGen, M. P. 1997. Chromosome doubling and fertility study of Alstroemeria aurea $\times A$. caryophyllaea. Euphytica, 94, 75-81.

MURASHIGE, T. AND SKOOG, F. 1962. A revised medium for rapid growth and bioassays with tobacco tissue culture. Physiol. Plant, 15, 473-497.

RAMANNA, M. S. 1983. First division restitution gametes through fertile desynaptic mutants of potato. Euphytica, 32, 337-350.

RAMANNA, M. S. 1991. Somatic vs. meiotic doubling of chromosomes in plants: implications for polyploidy in breeding. In: Kimber, G. (ed.) Proceedings of the 2nd International Symposium on Chromosome Engineering in Plants, pp. 118-127. University of Missouri-Columbia.

RAMANNA, M. s. 1992. The role of sexual polyploidization in the origins of horticultural crops: Alstroemeria as an example. In: Mariani, A. and Tavoletti, S. (eds) Proceedings of Workshop: Gametes with Somatic Chromosome Number in the Evolution and Breeding of Polyploid Polysomic Species: Achievements and Perspectives, pp. 83-89. Tipolitografia Porziuncola, Assisi (PG) Italy.

TSUCHIYA, T. AND HANG, A. 1989. Cytogenetics in the genus Alstroemeria. Herbertia, 45, 163-170. 